\title{
Optimeret brug af geodata - udvikling af SiteFX til danske forhold
}

\section{Af geolog Peter Scharling, GEUS}

Indtil nu har firmaer og institutioner ikke haft adgang til et værktøj, der effektivt har formået at integrere og strukturere data fra Jupiter, Gerda samt lokale projektdata. Her præsenteres værktøjet, SiteFX - en geodatabase, der er videreudviklet til nem og ligefrem håndtering af alle danske såvel som udenlandske geodata. SiteFX indeholder ligeledes et modul til effektiv visualisering, analyse og rapportering af geokemiske data.

I de senere år er de nationale geodatabaser, Jupiter (geologi, geokemi og hydrologi) og Gerda (geofysik), udbygget kraftigt samt blevet gjort offentligt tilgængelige. Desværre har der manglet en integrerende platform, hvorfra personer uden specifikke databasekundskaber har kunnet få direkte og let adgang til at udforske de mange spændende geologiske og geofysiske data, der efterhånden er indsamlet. Yderligere har der manglet et værktøj, der kan kombinere data fra de nationale databaser med lokale projektdata.

I erkendelse heraf har det canadiske software-firma EarthFX (www.earthfx.

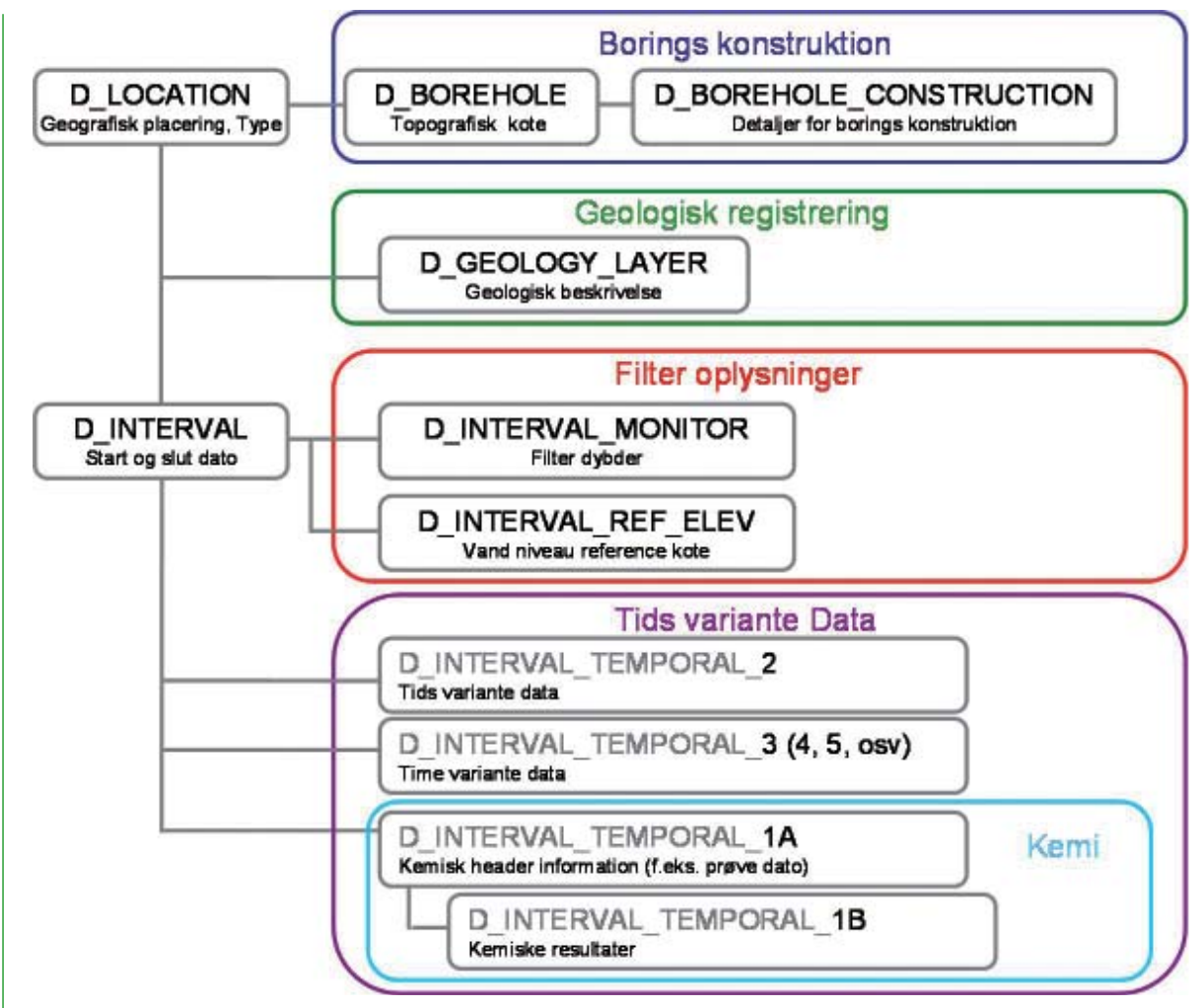

Opbygningen af SiteFX's geodatabase med 4 hovedinddelinger: Boringskonstruktion, Geologi, Filteroplysninger og tidsvarierende data som geokemiske analyser. (Grafik: Forfatteren modificeret efter EarthFX)

com) efter samtaler med GEUS og Ejlskov $\mathrm{A} / \mathrm{S}$ videreudviklet deres egen geodatabase, SiteFX, til at kunne håndtere alle danske

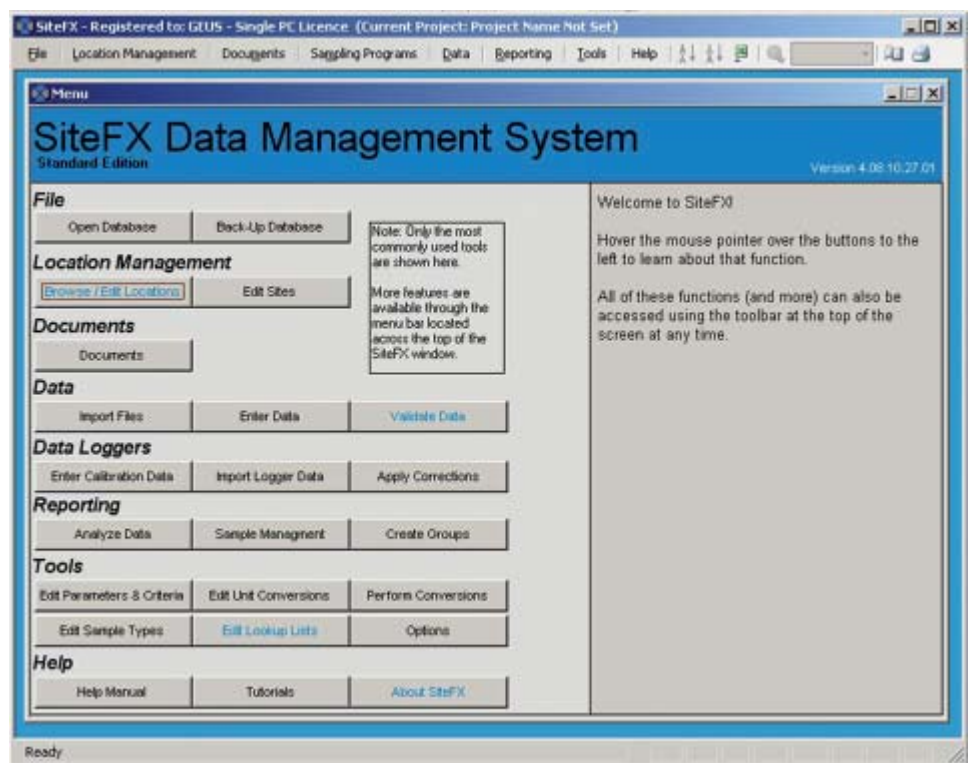

Dataadgangsmenuen for SiteFX. Herfra kan man bl.a. hurtigt få adgang til boringer, importere nye data eller analysere kemiske data. (Grafik: Forfatteren) geodata - nationale som lokale - på en effektiv, brugervenlig måde. Illustrationerne i denne artikel bygger på data fra Jupiter og Gerda, men det kunne lige så vel være data fra andre projekter.

\section{Databaser og SiteFX}

En ordentlig database til styring af ens data er fundamentet for ethvert vellykket projekt. Hvis man ikke har styr på data og mangler adgang til dem, kan man ikke visualisere, analysere og modellere korrekt. Databaser er dog mange forskellige ting og kan have forskellige fordele og ulemper. Nogle databaser som fx Microsoft Access er meget brugervenlige, men mangler en del, når det gælder indtastning af data samt hastigheden ved udførelse af opgaver. Andre databaser som Oracle og SQL Server har fokus på håndtering af store mængder data samt høj hastighed; de er dog gået på kompromis med brugervenligheden, og det er ikke ligetil for ikke-fagfolk at anvende disse systemer. SiteFX er basalt set en brugerflade til at fylde data ind i og trække data ud af en så- 


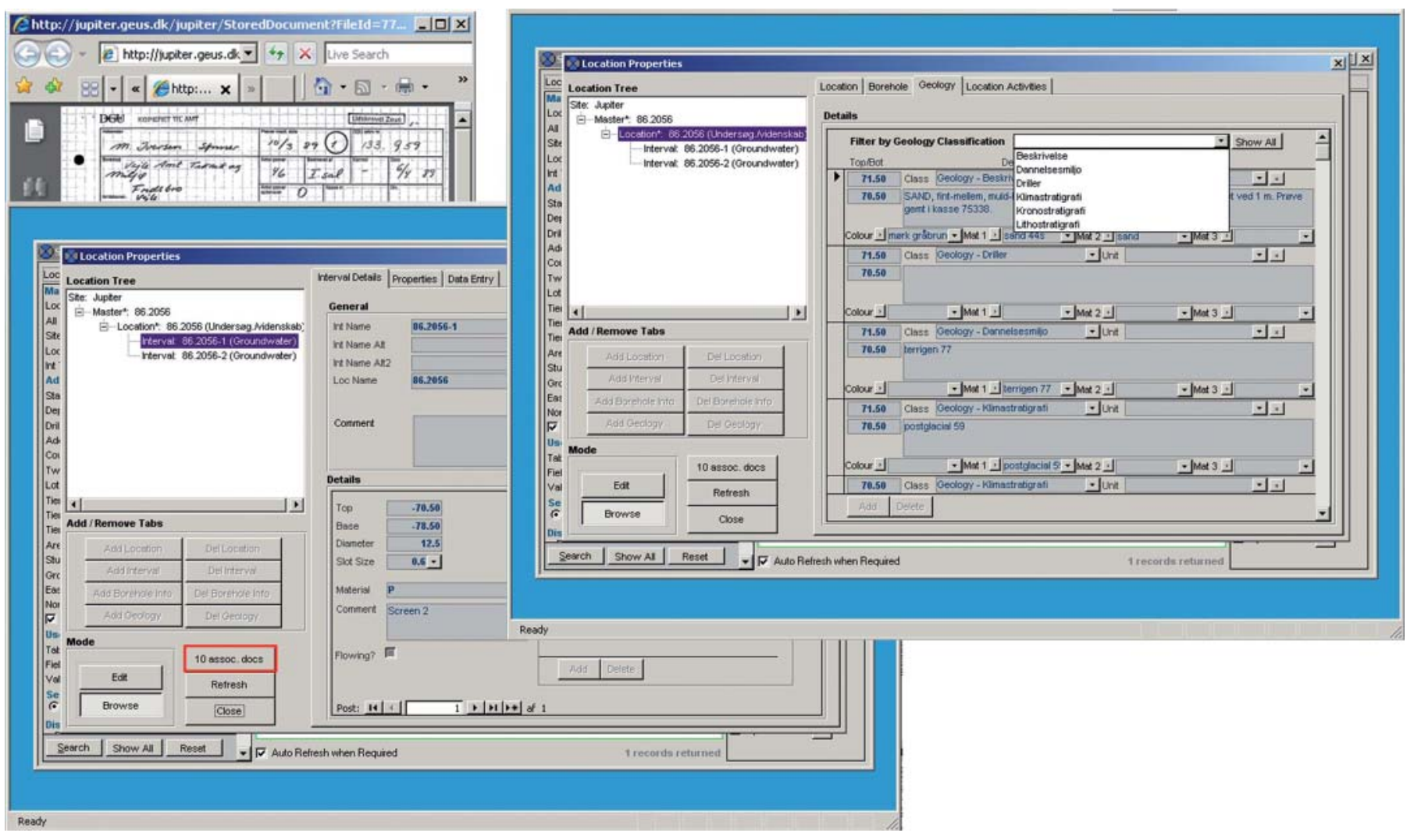

Til højre ses de geologiske data med mulighed for at valge forskellige geologiske beskrivelser, der alle findes i Jupiter. Øverst til venstre ses en af de scannede borerapporter, som der er direkte adgang til inde fra SiteFX. Nederst til venste ses data for boringens filtre. (Grafik: Forfatteren)

dan database. SiteFX genererer selv de tabeller og felter, som databasen består af, og man kan vælge mellem at bruge den brugerven- lige, men langsomme og størrelsesbegrænsede Access database eller en af de hurtigere, men sværere databaser som SQL Server og
Oracle. Fordelen ved at bruge SiteFX er, at brugerfladen er den samme, uanset hvilken database data ligger i. Inde fra SiteFX er det

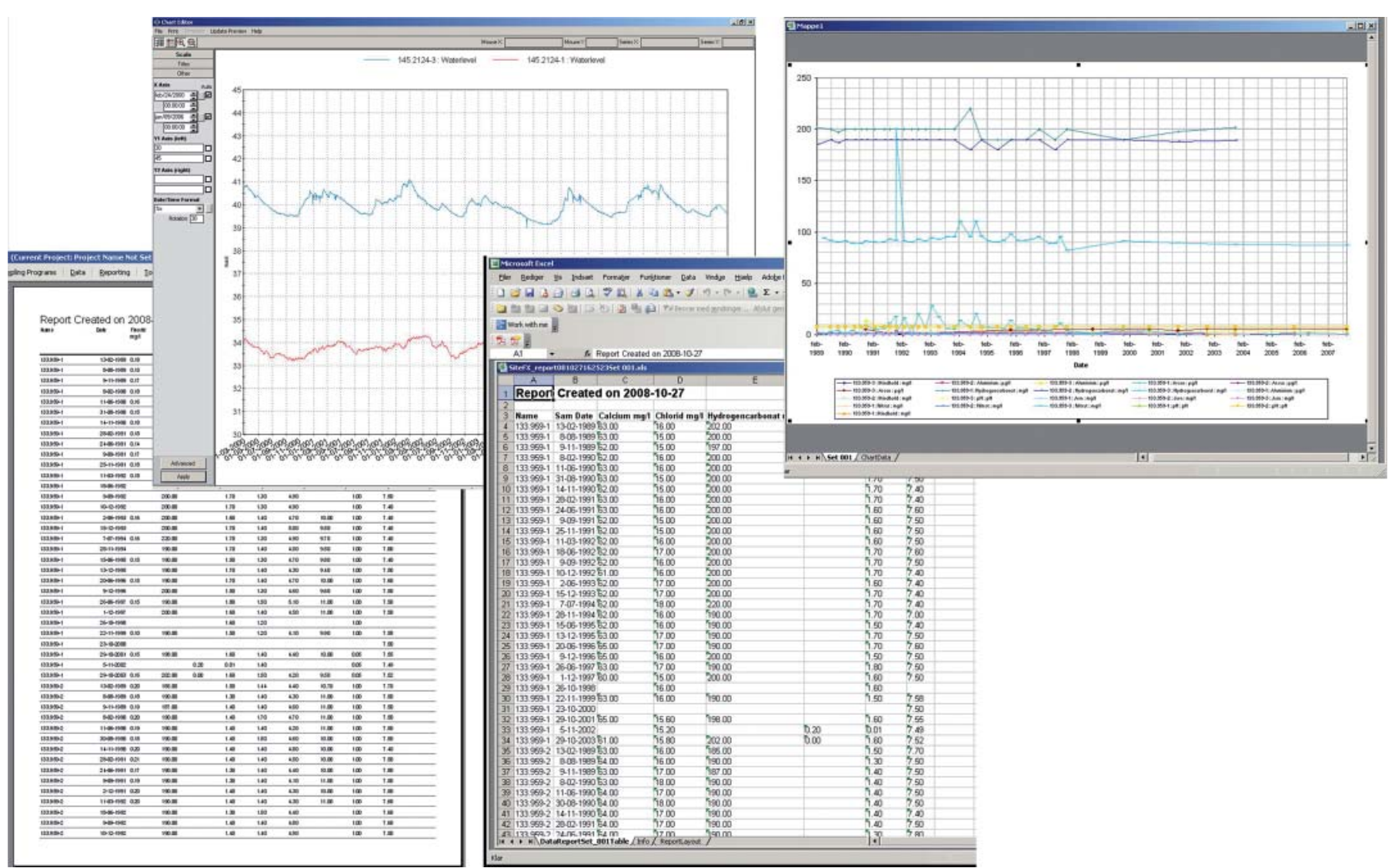

SiteFX genererer både rapporter og grafer for geokemiske data og vandniveaudata. Desuden kan data importeres direkte ind i Excel til videre bearbejdning både som rapport og graf. Grafik: Forfatteren) 


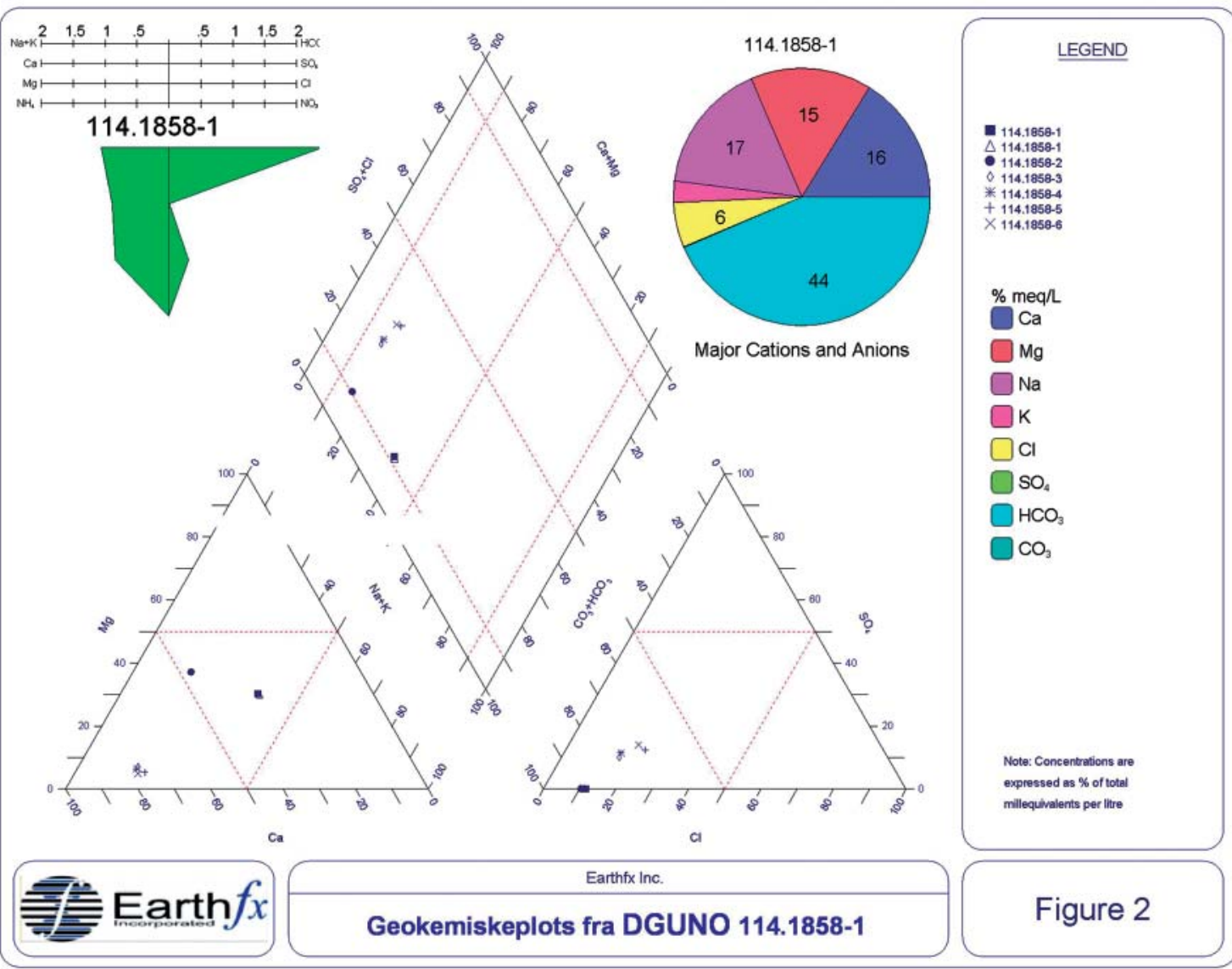

ligeledes muligt at skifte database, så man kan bruge SiteFX til at få adgang til projekter, der ligger på forskellige databaser.

\section{SiteFX}

SiteFX er inddelt i 3 hovedområder:

1. Håndtering af boringer og boringsoplysninger.

2. Import af data relateret til boringerne (kemi, vandniveauer, pumpning, geofysik m.m.).

3. Analyse og afrapportering af de importerede data.
Man har adgang til boringerne gennem en lang række forskellige søgekriterier, der kan være baseret på eksakte boringsnumre, projekter, geografiske placeringer, dybder m.m. Desuden er det også muligt at definere sit eget søgekriterium ved selv at angive en tabel, et felt og en værdi for søgningen. Når man har udvalgt en boring, får man adgang til alle oplysninger relateret til boringen, så som områdebeskrivelser, boringskonstruktion geologi, status og relaterede dokumenter. Herinde fra er det muligt at oprette nye boringer eller at se og rette i data for allerede oprettede boringer. SiteFX importerer data enten ved manuel indtastning eller automatisk import af filer. Den manuelle indtastning af kemidata, vandniveauer eller andre relevante parametre er mulig, når der er valgt en boring eller et filter, som data skal relateres til. Hvis man har store mængder data, som skal ind i databasen som fx kemiske analyser fra et analyse-laboratorium eller geofysiske logs, er der udviklet automatiske importfunktioner, så data bliver trukket direkte ind i databasen og placeret de rigtige steder.

SiteFX udmærker sig ved et meget let tilgængeligt og samtidigt stærkt analyse- og rapporteringsmodul for de geokemiske data. Man udvælger et antal boringer eller filtre, som analysen skal baseres på. Derefter listes alle tilgængelige parametre eller et udvalg baseret på foruddefinerede parametergrupper (en parametergruppe er en individuel gruppering af parametre, der navngives specifikt og derefter kan genbruges ved se- nere analyser). Til slut vælges det ønskede output med et udvalg, der spænder meget bredt. Der kan vælges den rå forespørgsel med data direkte fra databasen, grafer der viser de enkelte parametres udvikling over tid, rapporter der viser de ønskede data, Excel-grafer og rapporter, der tillader direkte korrektion, fordi de rå data bliver importeret med over i Excel-arket eller i en meget bred vifte af tilgængelige geokemiske plots. Det er muligt at gemme alle indstillingerne fra udvælgelsen af boringer og filtre, hvilke parametre der skal indgå i analysen samt opsætningen for det ønskede output. Denne mulighed bevirker, at man hurtigt og effektivt kan generere nye outputs, når der er kommet nye data til uden at skulle gennem den indledende udvælgelse og opsætning mere end én gang.

\section{Databasetypen}

Da SiteFX er udviklet til at håndtere mange forskellige typer databaser, er der i dette tilfælde valgt en database med "power". Det skyldes, at når der arbejdes med så store datamængder som Jupiter og Gerda, vil Access have svært ved at fortage de ønskede forespørgsler i et acceptabelt tempo. Den valgte database er SQL Server Express (SSE), som er en gratis version af SQL Server. SSE besidder samme "power" som SQL Server, men har bl.a. en begrænsning i databasestørrelsen på 4 GB. Når SSE er installeret, vil SiteFX automatisk danne SSE-databaser af de downloadede Jupiter- og Gerda-data samt yderligere lave en direkte Access-ad- 


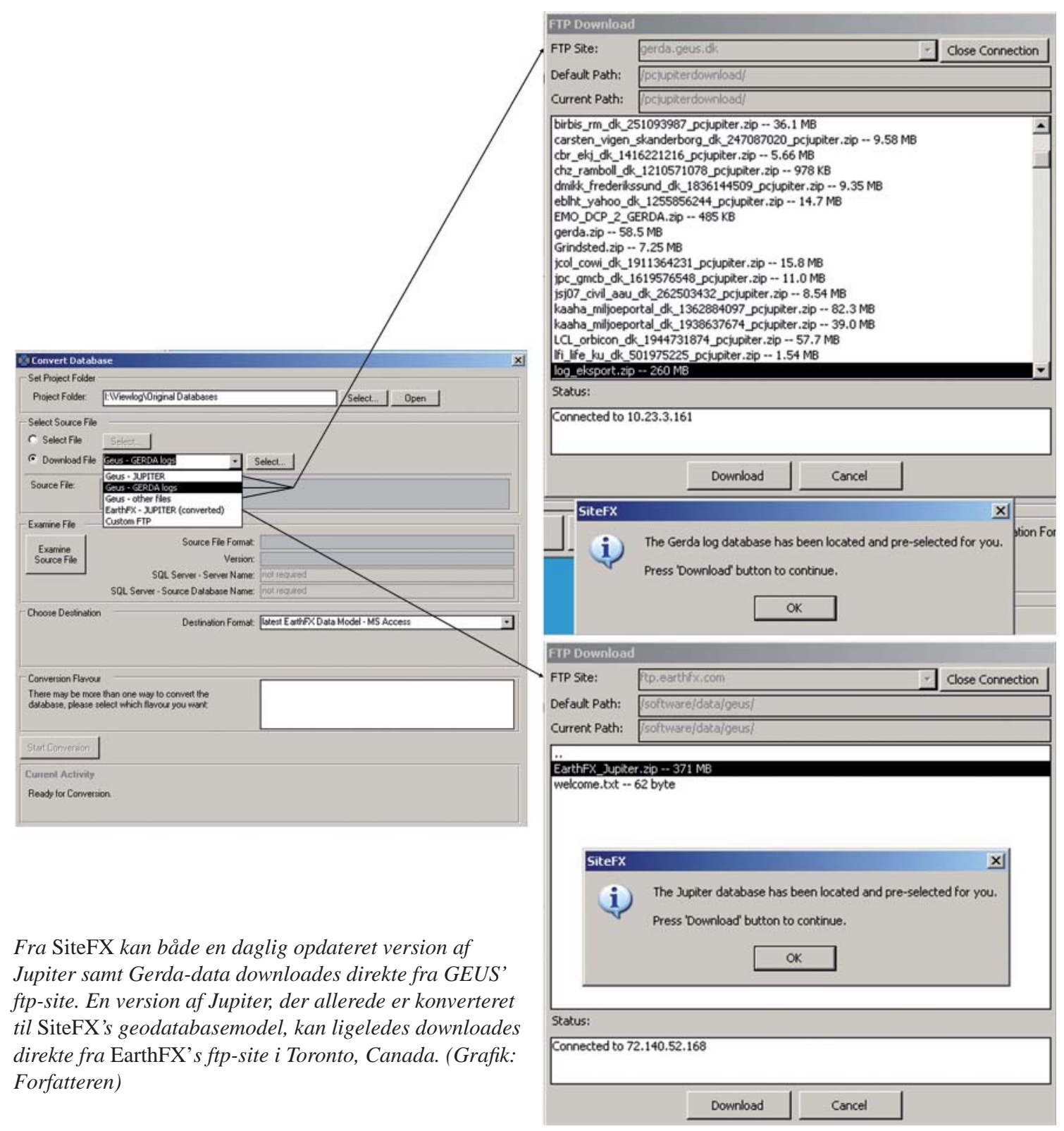

gang til hver af databaserne for dem, der gerne vil have adgang til de rå data, men samtidig ikke ønsker at sætte sig ind i SSE.

\section{Jupiter og Gerda i SiteFX}

EarthFX har konverteret Jupiter til den underliggende geodatabase-model for SiteFX. Det gør, at man inde fra SiteFX nu kan få adgang til alle de data, som ligger i Jupiter, og udnytte de værktøjer, der er udviklet til analyse og rapportering af data.

For at få adgang til Jupiter er der lavet en importfunktion inde fra SiteFX, hvor man kan vælge at hente Jupiter direkte fra GEUS' ftp-site eller fra EarthFX i Toronto, Canada. GEUS udtrækker dagligt Jupiter og lægger den frit tilgængeligt ud på deres ftpsite. Hvis man vælger denne mulighed, skal man dog selv konvertere Jupiter til SiteFX lokalt, hvilket kan tage flere timer. Derfor har man den mulighed at vælge en allerede konverteret og ligeledes dagligt opdateret version af Jupiter fra EarthFX og derved spare tiden til konvertering. Efter endt konvertering til SiteFX-format eller direkte download af den konverterede Jupiter, kan SiteFX derefter, hvis det ønskes, bruge den nye database som arbejdsdatabasen.

Den samme import/konverteringsfunktion bruges også til at hente Gerda-databasen fra GEUS' ftp-site. Da Gerda er meget stor og indeholder mange forskellige typer data, er det muligt at hente forskellige dele af databasen separat. Selve log-delen af Gerda kan vælges specifikt fra SiteFX, og den henter et udtræk, som GEUS opdaterer én gang om ugen. Ønskes andre dele af Gerda, kan man med fordel bruge dataadgangssiden, http://gerda.geus.dk/index.html, hvor man selv kan definere og navngive det ønskede udtræk ud fra kriterier som Datatyper, UTM-område, Projekter, Regioner, Kommuner, Periode m.m. Når det ønskede udtræk er genereret, får man automatisk en e-mail fra GEUS, hvorefter SiteFX bruges til at hente filen.

\section{Rettelse af fejl i Jupiter}

Da det af og til er nødvendigt at foretage en rettelse i Jupiter, er der udviklet en metode, hvor rettelser bliver gemt også efter opdatering med en ny version af Jupiter. Det er ligeledes muligt at slå rettelserne til og fra, da de enkelte rettelser bliver gemt i en separat tabel med et tilhørende "aktivitets-felt".

Visualisering, analyse og modellering SiteFX bruges til at strukturere alle typer geodata samt til analyse og rapportering af tidsvariable data som kemi-, vandniveau-, pumpe- og lignende data. Når der skal arbejdes med data på kort (2D), langs tværsnit, i 3D eller laves log-rapporter kan programmet Viewlog bruges (se "Optimeret 3D-modellering” i dette nummer af GeologiskNyt). Det specielle ved Viewlog er, at det trækker data direkte fra databaserne, derfor vil projektet altid bestå af de nyeste data fra databasen (Da SiteFX "bare" strukturerer data i en normal database, kan data dog frit eksporteres og vil ligeledes være tilgængelige for alle programmer, som kan hente data fra en database). Når det kombineres med muligheden for at opdatere med de nyeste data fra Jupiter og Gerda gennem 


\section{Sitefx}

\section{VIEWLOG}

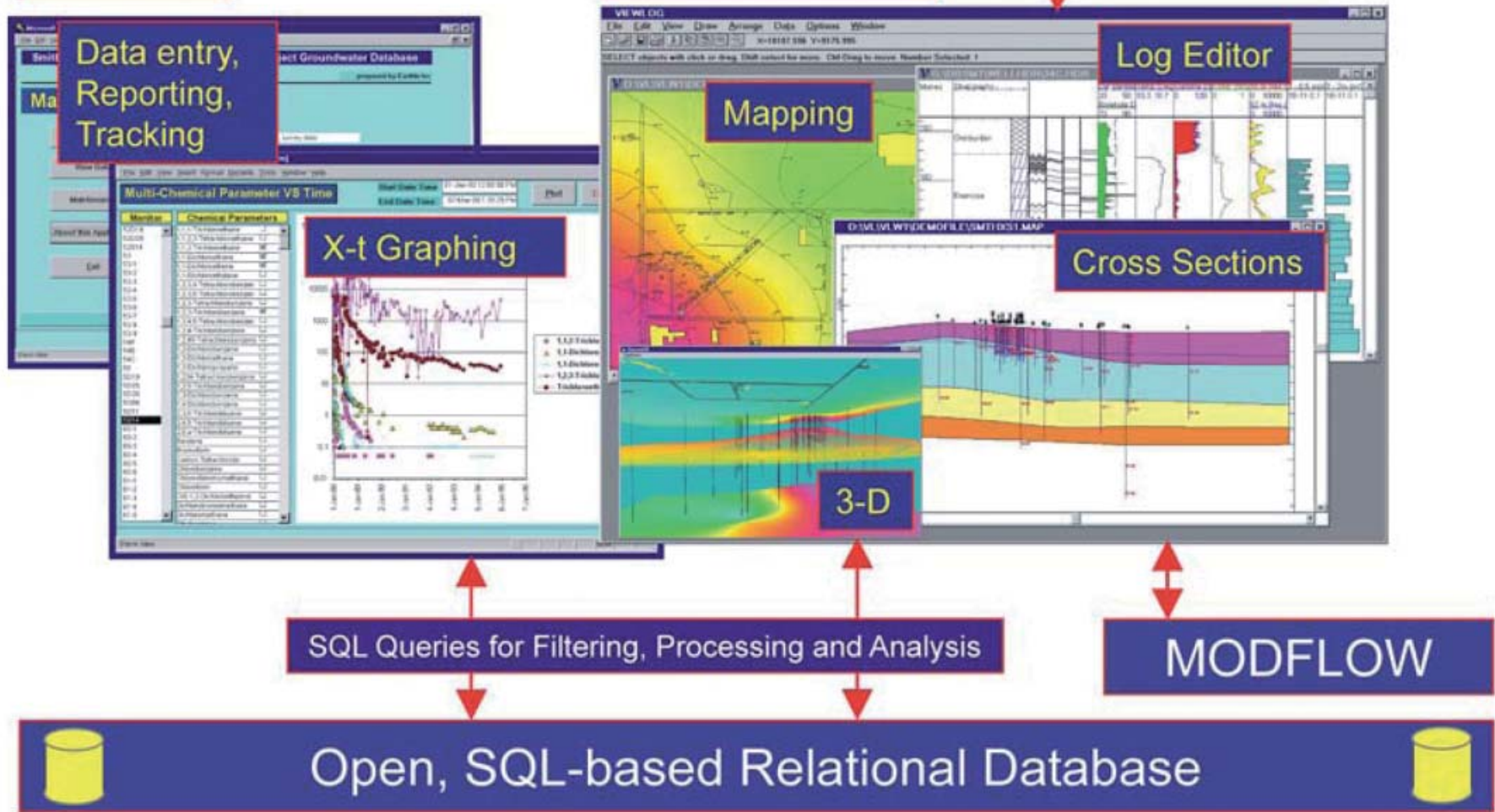

Samspillet mellem SiteFX, Viewlog og den underliggende database. Fra Viewlog-Manualen 2004. (Grafik: EarthFX's forside til Viewlog-manualen)

SiteFX, vil projektet altid have adgang til de nyeste data, hvad enten det drejer sig om kemiske-, hydrologiske- eller geologiske data. Viewlog begrænser ikke brugeren, i hvilke data der skal anvendes, eller hvorledes de skal sammensættes, da brugeren selv definerer, hvilke data som skal bruges.

Ved at anvende data direkte fra databaserne undgår man også et andet stort problem ved langstrakte projekter eller ved efterfølgende opdateringer. Mange typer software udviklet til at arbejde med geodata importerer data direkte ind i et special-udviklet filformat, der er unikt for det pågældende program. Det betyder, at i forbindelse med opdateringer skal der ofte startes helt forfra med import af data samt de efterfølgende udvælgelser og rettelser. Reelt bety- der dette som oftest, at hele projektet skal genopsættes. Dette problem er elimineret ved at trække data direkte fra databaserne, således at projektet ligeledes opdateres automatisk med databasen.

\section{SiteFX til mindre projekter}

SiteFX er udviklet til at håndtere alt fra én boring til adskillige millioner boringer. Antallet af tabeller og felter er det samme for den bagvedliggende database, det er kun mængden af data, som varierer. Et eksempel er firmaet Ejlskov A/S, der bl.a. arbejder med forureningsundersøgelser baseret på in situ-måling af forurening i jord og grundvand, og nu tester styring af alle deres data gennem SiteFX. Der er udviklet en automatisk importer til deres logdata, som derefter er direkte tilgængelige på overfladekort, til generering af log-rapporter eller yderligere tolkning. Geologien og andre relevante data for projektet er også styret af SiteFX og deres logdata samt de geologiske og tolkede data kan nemt kædes sammen i én fælles log-rapport, hvis det ønskes.

Udviklingen af Site $F X$ til at håndtere danske geodata giver brugere uden en stor databaseafdeling i ryggen en unik mulighed for at udnytte potentialet i de nationale databaser. Der er også mulighed for en effektiv integrering af lokale projekter med data fra Jupiter og Gerda, hvilket før voldte en del problemer. Det er heller ikke længere et problem, at rettelser i Jupiter går tabt ved opdatering af en nyere version. 